Erratum

\title{
Erratum: Ellegård, K. and Palm, J. Who Is Behaving? \\ Consequences for Energy Policy of Concept \\ Confusion. Energies 2015, 8, 7618-7637
}

\section{Energies Editorial Office}

Received: 20 November 2015; Accepted: 18 December 2015; Published: 21 January 2016

Academic Editors: Mark Lemon and Andy Wright

MDPI AG, Klybeckstrasse 64, CH-4057 Basel, Switzerland

We wish to make the following correction to the published paper [1]. Figure 4 was duplicated with Figure 2, while the correct Figure 4 was not included. Therefore the following figure (where it is labeled Figure 4):

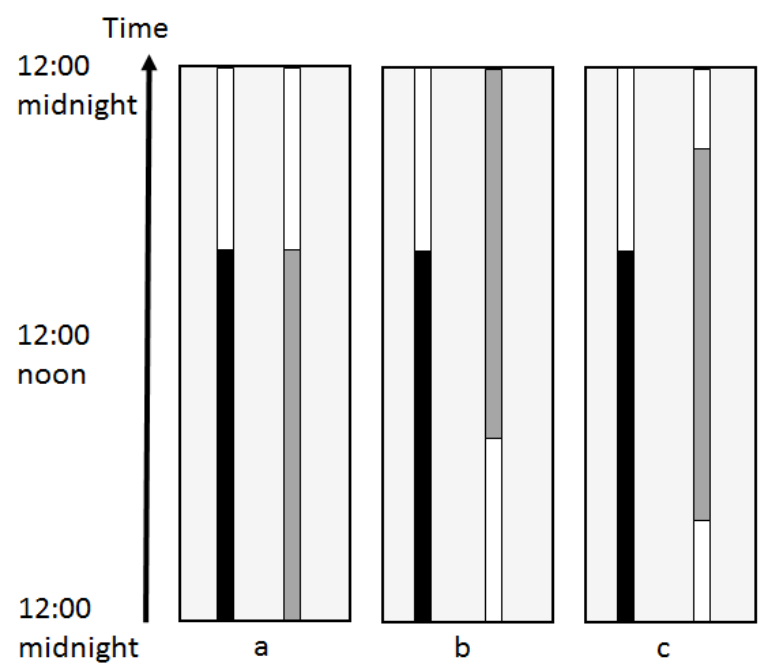

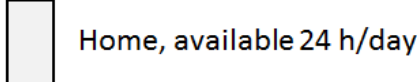

Household member who recieves the bill Time in the home

Time away from home Household member not recieving the bill

Time in the home

Time away from home

is replaced with:

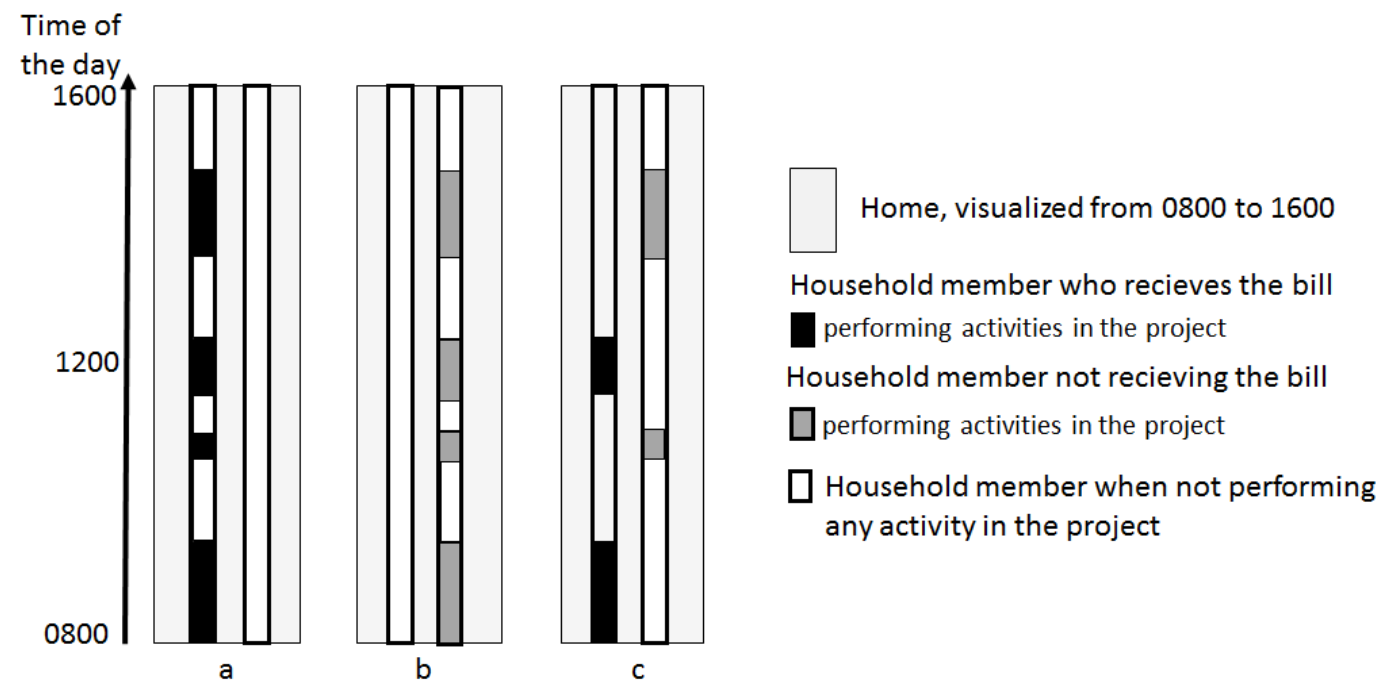


We apologize for any inconvenience caused to the readers by these changes.

\section{Reference}

1. Ellegård, K.; Palm, J. Who is behaving? Consequences for energy policy of concept confusion. Energies 2015, 8, 7618-7637.

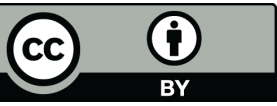

(C) 2016 by the author; licensee MDPI, Basel, Switzerland. This article is an open access article distributed under the terms and conditions of the Creative Commons by Attribution (CC-BY) license (http://creativecommons.org/licenses/by/4.0/). 